\title{
Obliczeniowe strumienie objętości gazów stosowanych w spawalnictwie
}

\section{Computational streams of gas volumes used in welding engineering}

\section{STRESZCZENIE}

Do wyznaczenia w instalacjach gazowych średnic przewodów i spadków ciśnienia, konieczna jest znajomość obliczeniowych strumieni objętości projektowanego gazu. Niewiele jest informacji w literaturze dotyczących tego zagadnienia. Przedstawiona propozycja ma umożliwić określenie natężenia przepływu gazu w rurociągach z dokładnością wystarczającą do celów technicznych.

\section{ABSTRACT}

To establish pipe diameters and pressure drops in gas installations it is necessary to know computational streams of gas volumes designed for usage. The information about this problem is not available in the reference literature. The proposal presented here is to allow determination of gas flow rate in pipelines with an accuracy sufficient for technical objectives.

\section{Obliczeniowe strumienie objętości gazu}

Obliczeniowe strumienie objętości gazu są zależne od przeznaczenia punktów czerpalnych. Jeżeli instalacja wyposażona będzie tylko w jednotypowe punkty czerpalne, o uniwersalnym (wielofunkcyjnym) przeznaczeniu, obliczeniowe strumienie objętości, określić można z wzoru:

$$
\mathrm{V}_{\mathrm{og}}=\Sigma \cdot\left(\mathrm{n} \cdot \mathrm{V}_{\mathrm{rg}} \cdot \beta\right)
$$

Wartość strumienia jednostkowego Vrg przewidzianego na jeden punkt czerpalny, powinna być podana przez projektanta-technologa zakładu.

Przy zasilaniu w gaz urządzeń (automatów lub linii technologicznej) występują dwie możliwości określania obliczeniowego strumienia gazu $\mathrm{V}_{\text {og: }}$ :

- na podstawie podanego w projekcie technologicznym maksymalnego godzinowego zużycia gazu $\mathrm{V}_{\mathrm{hmax}}$.

- według bilansu ustalonego dla podanego programu produkcji, z określeniem przeznaczenia poszczególnych linii produkcyjnych, rodzaju materiału używanego do produkcji, sposobów spawania materiałów itp.

W większości przypadków instalacja gazowa jest przeznaczona do obsługi urządzeń (automatów, linii produkcyjnej) oraz zasila punkty czerpalne o wielofunkcyjnym i pomocniczym przeznaczeniu. Przy mieszanym układzie zasilania, obliczeniowe strumienie objętości gazu, określić możemy z wzoru:

$$
V_{\text {og }}=\Sigma\left(n_{1} \cdot V_{1 r g} \cdot \beta_{1}+n_{2} \cdot V_{2 r g} \cdot \beta_{2}+\ldots n_{u} \cdot V_{h m a x}\right) \beta_{c}
$$

Przewidziane dla urządzeń technologicznych lub punktów czerpalnych strumienie objętości gazu $\left(\mathrm{V}_{\mathrm{rg}}, \mathrm{V}_{\mathrm{hmax}}\right)$ powinny być podane w projekcie technologicznym. Jeżeli informacji takich technolog nie określi, wartości strumieni objętości gazu określić należy na podstawie wskaźników zużycia potrzebnych do przewidywanych czynności spawalniczych. Podane w literaturze wskaźniki zużycia gazu $[1 ; 4 ; 5$; 6] zestawiono w tablicach I i IV.

Stosując do osłony procesów spawania mieszaninę gazów,

Dr inż. Edmund Nowakowski - Politechnika Wrocławska wskaźniki poszczególnych rodzajów gazu ustalić należy na podstawie ich udziału w tym procesie.

Przewidując przyłącze gazu do urządzenia, obliczeniowy strumień objętości gazu powinien być podany przez producenta urządzenia. Gdy znane jest tylko średnie godzinowe zużycia gazu Vhśr, potrzebne do obliczeń maksymalne godzinowe zużycie, określić możemy z wzoru:

$$
V_{\text {hmax }}=K_{h} \cdot V_{h s ́ r}=(1,4-2) V_{h s ́ r}
$$

Wartość współczynnika godzinowej nierównomierności rozbioru gazu $\mathrm{K}_{\mathrm{n}}$ jest zależna od cykliczności pracy urządzenia.

\section{Współczynniki jednoczesności działania punktów czerpalnych}

Wartość współczynników jednoczesności działania punktów czerpalnych gazu jest zależna od wielu czynników i dlatego trudna jest do jednoznacznego określenia. W literaturze niewiele jest informacji o tych współczynnikach. Inne wartości współczynników $\beta$ przyjmować należy dla punktów czerpalnych ogólnego przezna-

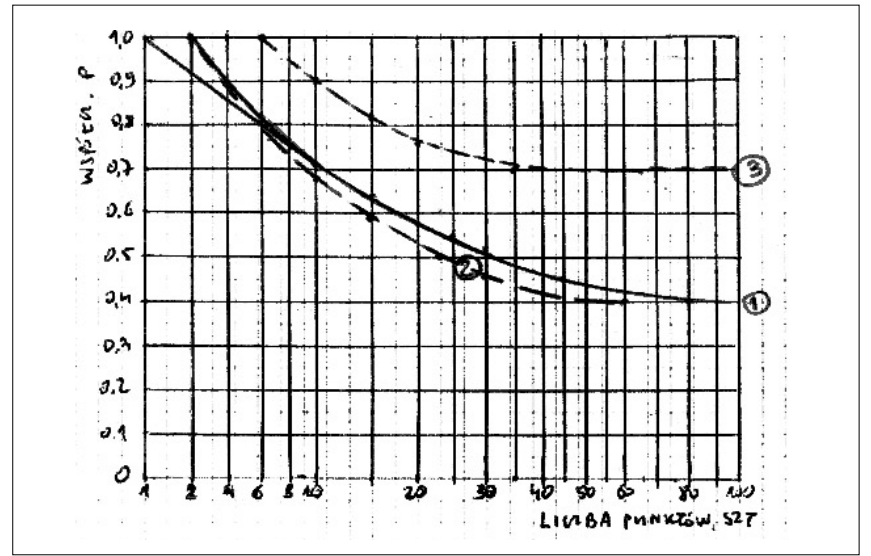

Rys. 1. Współczynniki jednoczesności działania punktów czerpalnych gazu 1 - sprężone powietrze [7; 8] i tlen [2]; 2 - dwutlenek węgla [3]; 3 - wartość proponowana dla $\beta_{\min }=0,7$. 
Tablica I. Minimalne zużycie acetylenu w spawaniu tlenowo-acetylenowym ( $\left.\mathrm{dm}^{3} / \mathrm{min}\right)$

\begin{tabular}{|c|c|c|c|c|c|c|c|c|c|c|c|c|c|}
\hline \multirow{2}{*}{ Rodzaj złącza } & \multicolumn{13}{|c|}{ Grubość blachy, mm } \\
\hline & 1 & 2 & 3 & 4 & 5 & 6 & 8 & 10 & 12 & 14 & 16 & 18 & 20 \\
\hline $\begin{array}{l}\text { 1. Spaw. na styk czołowy: } \\
\text { - w poz. poziomej }\end{array}$ & 1,7 & 3,5 & 4,2 & - & - & - & - & - & - & - & - & - & - \\
\hline - w poz. nachylonej & - & - & - & - & - & - & - & 16,7 & 20 & 20 & 23,6 & 30 & - \\
\hline $\begin{array}{l}\text { 2. Spaw. kątowe: } \\
\text { - wewnętrny }\end{array}$ & 2 & 4,2 & 6 & 8 & 10 & - & - & - & - & - & - & - & - \\
\hline \begin{tabular}{|l|} 
- zewnętrzny \\
\end{tabular} & 1,4 & 3 & 4,5 & 6 & 7,5 & 10 & 11,4 & 15 & - & - & - & - & - \\
\hline $\begin{array}{l}\text { 3. Spaw. w poz. poziomej: } \\
\text { - bez fazowania }\end{array}$ & - & 2,2 & 4,1 & 4,8 & 6 & 6,9 & - & - & - & - & - & - & - \\
\hline - fazowania V & - & - & - & 4 & 5 & 5 & 7,5 & 10,3 & 11,7 & - & - & - & - \\
\hline - fazowanie X & - & - & - & - & & - & 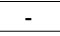 & - & - & 13 & 16,3 & 18 & 20 \\
\hline 4. Spaw. nad głową: & - & - & - & 5,3 & 7,7 & 8,9 & 12 & 14,9 & - & -1 & - & - & - \\
\hline \multicolumn{14}{|c|}{ 5. Cięcie mieszanką gazową $\mathrm{C}_{2} \mathrm{H}_{2}, \mathrm{O}_{2}, \mathrm{H}_{2}$ : } \\
\hline - zapotrzebowanie acetylenu & - & - & - & - & 3 & - & - & 3,6 & - & - & - & - & 4,2 \\
\hline
\end{tabular}

Uwagi: 1) Podane wskaźniki określono na podstawie informacji podanej przez Peszela [4] i dotyczą spawania metodą "w lewo", gdyż metoda "w prawo" jest mało stosowana. 2) Zużycie tlenu do spawania jest nieco wyższe od zużycia acetylenu, patrz uwaga w tabeli 1.

3) Wartości podane $w \mathrm{dmw}^{3} / \mathrm{min}$. przeliczamy na zużycie godzinowe $\mathrm{m}^{3} / \mathrm{h}$, przez zastosowanie mnożnika $\mathrm{m}=0,06$.

Tablica II. Orientacyjne zużycie argonu Ar do procesów spawalniczych ( $\left.\mathrm{dm}^{3} / \mathrm{min}\right)$

\begin{tabular}{|c|c|c|c|c|c|c|c|c|c|c|c|c|c|}
\hline \multirow{2}{*}{ Rodzaj spoiny i metody } & \multicolumn{13}{|c|}{ Grubość blachy, mm } \\
\hline & 1 & 2 & 3 & 4 & 5 & 6 & 8 & 10 & 12 & 14 & 16 & 18 & 20 \\
\hline $\begin{array}{l}\text { A/ Spawanie fukowe } \\
\text { 1. Spaw. aluminium: } \\
\text {-metoda TIG }\end{array}$ & $\begin{array}{l}4 \\
5\end{array}$ & $\begin{array}{l}5 \\
6\end{array}$ & $\begin{array}{l}6 \\
-\end{array}$ & $\begin{array}{l}8 \\
-\end{array}$ & $\begin{array}{c}8 \\
10\end{array}$ & $\begin{array}{c}8 \\
10\end{array}$ & $\begin{array}{l}10 \\
12\end{array}$ & $\begin{array}{l}10 \\
12\end{array}$ & $\begin{array}{l}12 \\
14\end{array}$ & $\begin{array}{l}12 \\
14\end{array}$ & $\begin{array}{l}12 \\
14\end{array}$ & $\begin{array}{l}14 \\
16\end{array}$ & $\begin{array}{l}14 \\
16\end{array}$ \\
\hline -metoda MIG & - & 12 & 14 & 14 & 15 & 15 & 18 & 18 & - & - & - & - & - \\
\hline $\begin{array}{l}\text { 2. Spaw. aluminium } \\
\text {-metoda TIG, spaw.: } \\
\text { poz. pozioma }\end{array}$ & - & 8 & 8 & 12 & 14 & 14 & 14 & 14 & 16 & 16 & 16 & - & - \\
\hline poz. naścienna & - & 8 & 10 & 12 & 12 & 14 & 14 & 14 & - & - & - & - & - \\
\hline pachwinowy & - & - & 12 & 12 & 12 & 14 & 14 & 14 & - & - & - & - & - \\
\hline $\begin{array}{l}\text {-metoda MIG, spaw.: } \\
\text { poz. pozioma }\end{array}$ & - & - & 14 & 14 & 16 & 16 & 18 & 18 & 20 & - & 20 & 20 & 20 \\
\hline poz. naścienna & - & - & - & 18 & 18 & 20 & 20 & 20 & 20 & 20 & 20 & 20 & 20 \\
\hline pachwinowy & - & - & - & 16 & 18 & 18 & 30 & 20 & 20 & 20 & 20 & 20 & 20 \\
\hline $\begin{array}{l}\text { 3. Spawanie miedzi } \\
\text {-metodą TIG }\end{array}$ & 5 & 5 & 6 & 6 & 8 & 8 & 10 & 10 & 12 & 15 & 15 & 15 & 15 \\
\hline $\begin{array}{l}\text { 4. Spawanie miedzi: } \\
\text {-metodą TIG, spaw.: } \\
\text { poz. pozioma }\end{array}$ & 8 & 8 & 10 & 10 & 10 & 12 & 12 & 12 & 14 & 14 & 14 & - & - \\
\hline Poz. naścienna & - & 8 & 8 & 10 & 10 & - & - & - & - & - & - & - & - \\
\hline Dwustronny & - & - & - & - & - & 10 & 12 & 16 & 20 & 20 & 20 & - & - \\
\hline $\begin{array}{ll}\text {-metoda MIG, spaw.: } & \\
\text { pzz. pozioma i pachwinowa } & \text { od } \\
& \text { do }\end{array}$ & - & - & - & $\begin{array}{l}15 \\
18\end{array}$ & - & $\begin{array}{l}18 \\
20\end{array}$ & $\begin{array}{l}18 \\
20\end{array}$ & $\begin{array}{l}18 \\
20\end{array}$ & $\begin{array}{l}18 \\
20\end{array}$ & $\begin{array}{l}18 \\
20\end{array}$ & $\begin{array}{l}18 \\
20\end{array}$ & $\begin{array}{l}18 \\
20\end{array}$ & $\begin{array}{l}18 \\
20\end{array}$ \\
\hline $\begin{array}{l}\text { B/. Spawanie plazmowe } \\
1 \text { / Spoina czołowa } \\
\text {-na plazmę Ar }\end{array}$ & - & 0,3 & - & - & - & - & - & 5,6 & - & - & - & - & - \\
\hline -na osłonę: Ar & - & 13 & - & - & - & - & - & 23 & - & - & - & - & - \\
\hline $\mathrm{H}_{2}$ & - & 1 & - & - & - & - & & 2 & - & - & - & - & - \\
\hline $\begin{array}{l}\text { 2. Stal kwasoodporna } \\
\text { dysze } 2 \mathrm{~mm}: \\
\text { - na plazmę Ar }\end{array}$ & 1 & 1 & 1,5 & 1,5 & - & - & - & - & - & - & - & - & - \\
\hline -ma osłonę: Ar & 4,65 & 4,65 & 4,65 & 4,65 & - & - & - & - & - & - & - & - & - \\
\hline $\mathrm{H}_{2}$ & 0,35 & 0,35 & 0,35 & 0,35 & - & - & - & - & - & - & - & - & - \\
\hline $\begin{array}{l}\text { dysza } 2,5 \mathrm{~mm}: \\
\text { - na plazmę } \mathrm{Ar}\end{array}$ & 1 & 1 & 1,5 & 1,5 & 2 & 2 & 2 & - & - & - & - & - & - \\
\hline -na osłonę: Ar & 4,65 & 4,65 & 4,65 & 4,65 & 7,44 & 7,44 & 7,44 & - & - & - & - & - & - \\
\hline $\mathrm{H}_{2}$ & 0,35 & 0,35 & 0,35 & 0,35 & 0,56 & 0,56 & 0,56 & - & - & - & - & - & - \\
\hline
\end{tabular}

Uwagi: 1) Wskaźniki niżzze dla spawania łukowego podaje Pilarczyk [5], wartości wyższe (szczegótowsze), Poradnik [1]. 2) Wskaźniki podane $\mathrm{w} \mathrm{dm}^{3} / \mathrm{min}$, przeliczenie na zużycie $\mathrm{m}^{3} / \mathrm{h}$ za pomocą mnożnika $\mathrm{m}=0,06$.

Tablica III. Zużycie dwutlenku węgla do spawania stali węglowych i nisko stopowych

\begin{tabular}{|c|c|c|c|c|c|c|c|c|c|}
\hline \multirow{2}{*}{ Rodzaj złącza } & \multicolumn{9}{|c|}{ Grubości blach, mm } \\
\hline & 2 & 3 & 4 & 5 & 6 & 8 & 10 & 12 & $15-20$ \\
\hline $\begin{array}{l}\text { A. Spaw. czołowe: } \\
\text { 1. Nieukosowane: } \\
\text { - poz. podolna pojed. } \\
\text { podw. }\end{array}$ & $\begin{array}{c}8-10 \\
-\end{array}$ & $\begin{array}{c}8-10 \\
-\end{array}$ & $\begin{array}{c}8-10 \\
12-15\end{array}$ & $12-15$ & $12-15$ & $\overline{14-17}$ & - & $\begin{array}{l}- \\
-\end{array}$ & - \\
\hline - poz. naścienna pojed. & $8-10$ & $8-10$ & $9-11$ & - & - & - & - & - & - \\
\hline - poz. pionowa poj. & $8-10$ & $8-10$ & $8-11$ & - & - & - & - & - & - \\
\hline $\begin{array}{r}\text { 2.Ukosowane V i X - poz. podolna pojed. } \\
\text { podw. }\end{array}$ & - & $\begin{array}{c}8-10 \\
-\end{array}$ & $\begin{array}{l}8-10 \\
9-11 \\
\end{array}$ & $\begin{array}{c}8-10 \\
12-15 \\
\end{array}$ & $\begin{array}{c}8-10 \\
12-15 \\
\end{array}$ & $\begin{array}{c}8-10 \\
12-15 \\
\end{array}$ & $\begin{array}{c}8-10 \\
12-15\end{array}$ & $\begin{array}{c}8-10 \\
12-15\end{array}$ & $\begin{array}{c}8-10 \\
12-15 \\
\end{array}$ \\
\hline $\begin{aligned} \text { - poz. naścienna - pojed. } \\
\text { - podw. }\end{aligned}$ & - & - & $\begin{array}{c}8-10 \\
-\end{array}$ & $\begin{array}{c}8-10 \\
-\end{array}$ & $\begin{array}{c}8-10 \\
-\end{array}$ & $\begin{array}{l}8-10 \\
9-11 \\
\end{array}$ & $\begin{array}{c}8-10 \\
12-15\end{array}$ & $\begin{array}{c}8-10 \\
12-15\end{array}$ & $\begin{array}{c}8-10 \\
12-15 \\
\end{array}$ \\
\hline - poz. pionowa & - & - & $8-10$ & $8-10$ & $8-10$ & $8-10$ & $8-10$ & $8-10$ & $8-10$ \\
\hline $\begin{array}{l}\text { B. Spaw. pachwinowe: } \\
\text { - poz. podolna }\end{array}$ & $8-10$ & $12-15$ & $12-15$ & $15-18$ & $15-18$ & $15-18$ & $15-18$ & $15-18$ & - \\
\hline - poz. naścienna & $8-10$ & $9-11$ & $12-15$ & $15-18$ & $15-18$ & $15-18$ & $15-18$ & $15-18$ & - \\
\hline - poz. pionowa & $8-10$ & $8-10$ & $8-10$ & $8-10$ & $8-10$ & $8-10$ & $8-10$ & $8-10$ & - \\
\hline $\begin{array}{l}\text { C. Spawanie punktowe: } \\
\text {-blachy o równej grubości }\end{array}$ & $18-20$ & $18-20$ & $18-20$ & $20-25$ & - & - & - & - & - \\
\hline
\end{tabular}

Uwagi: Wartości wskaźników podane w dm3/min przeliczany na zużycie godzinowe w m³/h, stosując mnożnik $\mathrm{m}=0,06$. PRZEGLĄD SPAWALNICTWA 1/2007 
Tablica IV. Minimalne zużycie tlenu do spawania acetylenowego ( $\left.\mathrm{dm}^{3} / \mathrm{min}\right)$

\begin{tabular}{|c|c|c|c|c|c|c|c|c|c|c|c|c|c|}
\hline \multirow{2}{*}{ Rodzaj złącza } & \multicolumn{13}{|c|}{ Grubość blachy, mm } \\
\hline & 1 & 2 & 3 & 4 & 5 & 6 & 8 & 10 & 12 & 14 & 16 & 18 & 20 \\
\hline 1. Spoina na styk: - poz. poziomy & 2 & 4,2 & 5 & - & - & - & - & - & - & - & - & - & - \\
\hline - poz .nachylona & - & - & - & - & - & - & - & 20 & 23 & 23 & 27 & 34,5 & - \\
\hline 2. Spoina kątowa: - wewnętrzny & 2,5 & 5 & 7,2 & 9,6 & 12 & - & - & - & - & - & - & - & - \\
\hline - zewnętrzny & 1,7 & 3,6 & 5,4 & 7,2 & 9 & 12 & 13,7 & 18 & - & - & - & - & - \\
\hline $\begin{array}{l}\text { 3. Spoina w poz. poziomej: } \\
\text { - bez fazowania }\end{array}$ & - & 2,7 & 5 & 5,8 & 7,2 & 8,3 & - & - & - & - & - & - & - \\
\hline - fazowanie V & - & - & - & 4,8 & 6 & 6 & 9 & 12 & 13,5 & - & - & - & - \\
\hline - fazowanie $X$ & - & - & - & - & - & - & - & - & - & 15 & 15,8 & 16,2 & 23 \\
\hline \multicolumn{14}{|c|}{ 5. Cięcie mieszanką tlen + acetylen + wodór: } \\
\hline - zużycie tlenu: & - & - & - & - & 12,5 & - & - & 20 & - & - & - & - & 29,5 \\
\hline
\end{tabular}

Uwagi: 1) Jeżeli znane jest zużycie acetylenu do procesu spawania, zapotrzebowanie tlenu określić możemy wskaźnikiem udziału tlenu odniesionym do acetylenu, który wynosi: - dla małych palników i grubości blach 1,2 - 1,3; - dla dużych palników i grubości blach 1,08 - 1,1.

2) Wartości podane $\mathrm{w} \mathrm{dm} 3 /$ min przeliczamy na zużycie $\mathrm{w} \mathrm{m} 3 / \mathrm{h}$, stosując mnożnik $\mathrm{m}=0,06$.

\begin{tabular}{|c|c|}
\hline \multicolumn{2}{|c|}{ Oznaczenia: } \\
\hline $\mathrm{n}$ & $\begin{array}{l}\text { - liczba punktów czerpalnych gazu o ogólnym } \\
\text { przeznaczeniu, szt., }\end{array}$ \\
\hline $\mathrm{n}_{1}, \mathrm{n}_{2}$ & - liczba jednotypowpch punktów czerpalnych gazu, szt., \\
\hline nu & $\begin{array}{l}\text { - liczba jednotypowych maszyn lub urządzeń o znanym } \\
\text { maksymalnym godzinowym zużyciu gazu, szt., }\end{array}$ \\
\hline$K_{h}$ & $\begin{array}{l}\text { - współczynnik godzinowej nierównomierności } \\
\text { zużycia gazu, }\end{array}$ \\
\hline $\mathrm{V}_{\mathrm{og}}$ & $\begin{array}{l}\text { - obliczeniowy strumień objętości gazu w rozpatrywanej } \\
\text { instalacji gazowej, } \mathrm{m}^{3} / \mathrm{h} \text {, }\end{array}$ \\
\hline $\mathrm{V}_{\mathrm{rg}}$ & $\begin{array}{l}\text { - obliczeniowy strumień objętości gazu przypadający } \\
\text { na jeden punkt czerpalny, } \mathrm{m}^{3} / \mathrm{h} \text {, }\end{array}$ \\
\hline $\mathrm{V}_{\text {hśr }}$ & $\begin{array}{l}\text { - średnie godzinowe zużycie gazu przez urządzenie } \\
\text { lub agregat, } \mathrm{m}^{3} / \mathrm{h} \text {, }\end{array}$ \\
\hline $\mathrm{V}_{\mathrm{hmax}}$ & $\begin{array}{l}\text { - maksymalne godzinowe zużycie gazu przez urządzenie } \\
\text { lub agregat, } \mathrm{m}^{3} / \mathrm{h} \text {, }\end{array}$ \\
\hline & $\begin{array}{l}\text { - obliczeniowy strumień objętości gazu roboczego } \\
\text { przewidziany dla jednego i jednotypowego punktu } \\
\text { czerpalnego gazu, } \mathrm{m}^{3} / \mathrm{h} \text {, }\end{array}$ \\
\hline$\beta$ & $\begin{array}{l}\text { - współczynnik jednoczesności działania punktów } \\
\text { czerpalnych gazu o ogólnym ich przeznaczeniu, }\end{array}$ \\
\hline$\beta_{1}, \beta_{2}$ & $\begin{array}{l}\text { - współczynniki jednoczesności działania jednotypowych } \\
\text { punktów czerpalnych gazu, }\end{array}$ \\
\hline$\beta_{c}$ & $\begin{array}{l}\text { - współczynnik jednoczesności działania poszczególnych } \\
\text { grup punktów czerpalnych gazu, }\end{array}$ \\
\hline$\beta_{\text {min }}$ & $\begin{array}{l}\text { - minimalne wartości współczynników jednoczesności } \\
\text { działania jednotypowych punktów czerpalnych dla } \\
\text { liczby punktów ( } \geq 30 \text { szt.). }\end{array}$ \\
\hline
\end{tabular}

\section{Wnioski}

- Wobec skromnych informacji literaturowych dotyczących określania strumieni objętości gazów stosowanych w spawalnictwie oraz równoczesności działania punktów czerpalnych tych gazów, przedstawiona propozycja ma umożliwić właściwy dobór średnic instalacji gazowych.

- Zasady powyższe należy stosować szczególnie tam, gdzie w projekcie technologicznym zakładu nie podano dostatecznych informacji do zaprojektowania instalacji gazowych.

- Ze względu na zbliżony przebieg wartości współczynników jednoczesności działania punktów czerpalnych gazów: sprężonego powietrza, tlenu i dwutlenku węgla, wartości te mogą być również stosowane dla innych gazów stosowanych w spawalnictwie. czenia, służących do prac pomocniczych w zakładzie, a inne dla jednotypowych urządzeń produkcyjnych lub linii produkcyjnych. Dla punktów czerpalnych ogólnego przeznaczenia, niezależnie od zastosowanego gazu, wartość współczynników jednoczesności działania $\beta$ określić możemy z rysunku. Dla niektórych gazów wartość tych współczynników jest podana w publikacjach: - dla tlenu [2], - dla dwutlenku węgla [3], dla sprężonego powietrza [7]. Gdy punkty czerpalne gazu zasilają urządzenia lub stanowiska technologiczne, określić możemy minimalne wartości współczynników jednoczesności działania punków czerpalnych (powyżej 30 szt. urządzeń) korzystając z zaleceń podanych w literaturze [1]:

- dla produkcji jednostkowej

- dla produkcji seryjnej

- dla produkcji wieloseryjnej i masowe

$$
\begin{aligned}
& \beta_{\text {min }}=0,3-0,4 \\
& \beta_{\text {min }}=0,4-0,7 \\
& \beta_{\text {min }}=0,7-0,8
\end{aligned}
$$

Jeżeli liczba urządzeń jest mniejsza niż około 30 szt. wartości współczynników jednoczesności działania urządzeń określić możemy:

- dla produkcji jednostkowej, według rozkładu podanego na rysunku dla punktów czerpalnych ogólnego przeznaczenia (krzywa 1),

- dla produkcji seryjnej i masowej, według zaproponowanego na rysunku rozkładu dla przyjętego współczynnika $\beta_{\min }=0,7$ (krzywa 3).

Współczynniki jednoczesności działania $\beta$ dotyczą jednotypowych punktów czerpalnych. Dobierając urządzenia zasilające instalację (stacje redukcyjne, stacje odgazowania, stacje sprężonego powietrza) zastosować możemy współczynnik jednoczesności działania poszczególnych grup punktów czerpalnych jednotypowych. Szacunkowa wartość tego współczynnika wynosi $\beta_{c}=(0,8$ $-0,85)$.

\section{Literatura}

[l] Poradnik Inżyniera. Spawalnictwo. Tom 1 i 2, WNT, Warszawa, 1983.

[2] Nowakowski E.: Wzory do obliczeń instalacji tlenowych w zakładach leczniczych. GWiTS 12/1/79.

[3] Nowakowski E., Antonowicz J., Kollbek B.: Zasady projektowania instalacji C02 w uzdrowiskach. Probl. Uzdrow. 3/1978.

[4] Pyszel Z.: Spawanie. Cz. I Zasady spawania acetylenowego stali. Wyd. II YMCA Genewa 1946.

[5] Pilarczyk J.: Technologia spawalnictwa. Polit. Śląska. Skrypt Nr 576/6 Gliwice 1975.

[6] Marcolla K.: Zarys spawalnictwa. PWN, Warszawa-Poznań 1981.

[7] Informator Projektanta Budownictwa Ogólnego. Instalacje Sanitarne, 9/1959 Obliczanie średnic sprężonego powietrza.

[8] Mechanik. Poradnik techniczny. Tom 5 cz. 2, PWN, Warszawa, 1955. 